Silvestra Mariniello

\title{
Repensar la poesía
}

La poesía no es un género

En un artículo publicado en 1959, que respondía a preguntas sobre la novela, la escritora italiana Elsa Morante criticaba la política de los géneros. El discurso sobre los géneros se fundamenta en convenciones escolares y está determinada por contingencias culturales siempre diferentes. Morante propone romper los límites de este discurso y define la novela como "toda obra poética en que el autor -mediante la narración fabricada de acontecimientos ejemplares [...] da toda entera su propia imagen del universo real [...]"- - ${ }^{1}$ La Ilíada y La Chanson de Roland, pero también los Sonetos de Shakespeare y el Canzoniere de Petrarca son novelas según esta definición.

Los géneros no se sostienen más, todo el sistema de valores que los expresaba es puesto en cuestión. La única posibilidad es la de la escritura de la "realidad", dice Morante en términos

${ }^{1}$ E. Morante, Opere, Mondadori, Milán, 1990, vol. II, p. 1498. 
pasolinianos. La escritura de la realidad no puede desembocar en una obra inscrita en un género, en una obra "literaria", se inscribe más bien en la experiencia, en la vida y produce a su vez la experiencia histórica, pero ¿cómo?

En el ensayo Por o contra la bomba atómica, Morante opone al escritor y al hombre de letras y define al escritor como "alguien que se interesa por todo lo que sucede excepto la literatura". ${ }^{2}$ El escritor, a quien también podemos llamar poeta -el poeta tiene la función de "impedir la desintegración de la conciencia humana en cotidiano, penoso y alienante uso con el mundo"- ${ }^{3}$ tiene como función oponerse a la "fea invasión de la irrealidad"4 escribiendo la "realidad". Por ejemplo, al escribir el horror de la bomba atómica y su pertenencia a la economía cultural de la sociedad occidental contemporánea. "Nuestra bomba es la flor, es decir, la expresión natural de nuestra sociedad contemporánea, así como los Diálogos de Platón son la flor de la ciudad griega". ${ }^{5} \mathrm{El}$ escritor-poeta es la conciencia de la "realidad", es aquel entre la masa que no se deja hacer, pero más que eso: mediante su escritura, su conciencia se convierte en un "ejemplo" y produce, al infinito, otras conciencias. "Cuando un poema se ha ido, no se detiene más; sino que corre y se multiplica llegando a todas partes, hasta donde el poeta mismo no se lo hubiera esperado."6 La poesía se convierte en acción.

En Auschwitz, Primo Levi se deja invadir por el canto de Ulises. Los versos dantescos se convierten en acción: crean una dinámica que transforma la experiencia histórica y mítica, producen un cambio al establecer un contacto entre temporalidades

2 E. Morante, op. cit., p. 1539.

${ }^{3}$ Ibidem, p. 1542.

${ }^{4}$ Ibidem, p. 1545.

${ }^{5}$ Ibidem, p. 1540.

${ }^{6}$ Ibidem, p. 1545. 
diferentes y experiencias diferentes. De igual forma, la escritura de Levi se traduce en acción, se constituye en ejemplo. En el coloquio de Nancy, dedicado a Primo Levi y el diálogo de los saberes, en 1996, una joven mujer ruandesa se levantó en un momento para decir que ella había oído, entre los testimonios de los sobrevivientes de las recientes masacres en Ruanda, el de un hombre que decía haber resistido a todo tipo de martirio gracias al ejemplo de Primo Levi.

El sistema hace todo lo posible para integrar al escritor, para asimilarlo. Morante propone entonces otra distinción: aquella entre escritor y escribiente. El escritor no pertenece a ninguna sociedad determinada, a ningún grupo, a ninguna categoría. El escritor escribe poesía [...] el resto (los géneros, el dialecto, la koiné, el estilo, la lengua literaria) no tiene importancia.

Canetti trabaja en la misma sintonía cuando analiza la frase de un autor anónimo fechada el 23 de agosto de 1939, que lo había llevado a la definición del poeta en tanto que el "guardián de las metamorfosis", definición a la cual regresaremos. Al principio, la frase lo había indignado por su aparente jactancia y se le había impuesto después en todo su sentido trágico.

"No obstante, todo terminó. Si yo fuera realmente un poeta, debería poder impedir la guerra".

Así, esta frase, que le había parecido arrogante, se cargaba ahora de "la confesión de una responsabilidad". Se trataba de la responsabilidad de las palabras hasta la constatación del. desfallecimiento y del fracaso total: cuando las palabras no logran impedir las guerras.

Muy a menudo, los críticos de Elsa Morante han dicho que su obra se caracteriza por su rechazo de la Historia. La oposición entre Historia y vida que sus escritos parecen poner en escena se resolvería a favor de la vida, o como uno de sus críti-

${ }^{7}$ E. Canetti, "Le métier du poéte", en La conciencia de las palabras, Albin Michel, París, 1984, p. 333 (trad. española, FCE). 
cos lo dice, a favor de "su rechazo anarquista y vitalista de la Historia". 8 Pero más que hablar de rechazo de la Historia, deberíamos hablar de reescritura de la Historia, de producción de la Historia más allá de los límites impuestos por la historiografía oficial.

En un estado de espíritu similar, en la misma época que Elsa Morante, Kateb Yacine, escritor militante argelino, decía: "el Coran, la Biblia, ciertas páginas de Marx, de Lenin, son para mí poesía." La puesta en cuestión de los géneros es el producto de las contingencias históricas. El fin de la "posguerra" en Europa, la guerra en Argelia tienen efectos en el orden institucional de las disciplinas y de los discursos, la poesía se da a repensar. ¿Por qué la poesía?

\section{La Poesía y la Historia}

Cuando comenzamos a cuestionar este orden casi "natural" vemos que, en efecto, la relación poesía-Historia es bastante compleja y dinámica.

En Hölderlin y la esencia de la poesía, Heidegger define la poesía como "el fundamento que sostiene la Historia": 10 poesía, lenguaje, temporalidad, Historia se hacen posibles por el mismo movimiento. Lo que constituye al ser humano es su posibilidad de testimoniar "su pertenencia a la Tierra", este testimonio se hace mediante el lenguaje y precisamente mediante el lenguaje en forma de diálogo, y al hacerlo, se "historializa", se produce como Historia. El tiempo historial que Heidegger llama también el tiempo desgarrado (en pasado, presente y futuro) y el lenguaje son contemporáneos, la poesía es el adveni-

${ }^{8}$ S. Guglielmino, Guida al Novecento, Principato Ed., Milán, 1992, p. II/794.

${ }^{9}$ K. Yacine, Le poéte comme un boxeur. Entretiens 1958-1989, Seuil, París, 1994, p. 45.

10 M. Heidegger, Approche de Hölderlin, Gallimard, París, 1962, p. 54. 
miento de este tiempo historial. El ensayo de Heidegger es muy rico e intenso y desgraciadamente no hay tiempo aquí de discutir todas sus implicaciones. Debo concentrarme entonces en la última parte. Como conclusión a su ensayo, Heidegger dice:

Hölderlin poematiza la esencia de la poesía, pero no en el sentido de un concepto que tomaría un valor intemporal. Esta esencia de la poesía pertenece a un tiempo determinado. Lo cual no implica de ninguna manera que simplemente se vuelva conforme a este tiempo como si éste subsistiera ya antes que ella. Pero al fundar de nuevo la esencia de la poesía, Hölderlin comienza por determinar así un tiempo nuevo. Es el tiempo de los dioses desaparecidos $y$ del dios que va a llegar. Es el tiempo del desamparo, porque ese tiempo está marcado con una doble falta y una doble negación: el "no más" de los dioses desaparecidos y el "aún no" del dios que va a llegar."

El universo que habitamos no es más el de la hegemonía de la prosa, de la consolidación de la relación entre la cultura y el Estado, de la distinción entre la historia (lo verdadero) y el mito (lo falso). Vivimos en el después de la prosa: en un universo donde alimentada por la economía de consumo, la tecnología creó una nueva oralidad, en un universo que nos impone repensar todas nuestras categorías epistemológicas. Vivimos la transición de una hegemonía a otra, un tiempo de "desamparo" si queremos retomar a Hölderlin y a Heidegger, él marcado también por una doble falta: el "no más" de ciertos dioses desaparecidos (el Estado, la escritura, la Historia lineal y progresista, etc.) y el "aún no" de aquellos que van a venir. La Shoah y la experiencia de los campos de concentración marcan para siempre el corte y la distancia infranqueable entre los dos: el "no más" y el "aún no".

${ }^{11}$ M. Heidegger, op. cit., p. 60. 
¿Y la poesía? ¿La poesía, esa "combinación de materialidad y de inmediatez", puede ayudarnos a redefinir nuestro modo de operar en el mundo, nuestro modo de ser "historiales"? ¿Puede constituir una forma de mediación histórica que nos permita asimilar las experiencias? ¿Cómo? ¿Es aún necesario hablar de poesía?

Mahmoud Darwich es un poeta palestino contemporáneo, exiliado en Francia. Cuando lee sus poemas, hasta 20,000 personas vienen a escucharlo. En Une mémoire pour l'oubli, escribe: "Estas canciones tallan en piezas la armada de los invasores, y el suelo de la patria fue liberado, estrofa tras estrofa". ${ }^{12}$

- Esta imagen evoca con fuerza la materialidad de la poesía, su dimensión concreta, su "eficacia", su historialidad: hace la Historia, produce cambios. Más adelante, hacia el final del libro, el escritor se interroga directamente sobre la poesía. Un amigo poeta se suicidó "no para testimoniar algo sino para no ser el testigo de nada", 13 a la preguntà, ¿qué es la poesía?, la voz de ese relato no narrativo, responde: la poesía "Es escribir ese silencio universal, último, total". ${ }^{14}$ Une mémoire pour l'oubli es un "relato" cuyo subtítulo es el siguiente: El tiempo: Beyrouth. El lugar: Un día de Agosto 1982. Así como las coordenadas espacio-temporales, los límites del género también se transtornan. Sería interesante, quizás, comparar esta escritura del silencio con la "poesía que se empeña en decir", "en hacer y deshacer las riberas del silencio"15 del que habla Ben Jelloun en su introducción a La remontée des cendres, una colección de poemas que escribió para los muertos de la Guerra del Golfo. ¿Escribir el silencio o hablar para romper el silencio? Hay un abismo entre los dos. Para escribir el silencio se

12 M. Darwich, Une mémoire pour l'oubli, Actes Sud, Arles, 1994, p. 18.

${ }^{13}$ M. Darwich, op. cit., p. 132.

14 Ibidem.

15 T. Ben Jelloun, La remontée des cendres, Seuil, París, 1991, p. 6. 
necesita reinventar la escritura, asumir un desafío total, dejarse transformar por la Historia. Escribir contra el silencio, se puede hacer sin poner en cuestión las categorías fundadoras del conocimiento y de la acción, manteniéndose como el sujeto de la Historia.

En una entrevista televisada con Roger Rosenblatt, ${ }^{16}$ Lanzmann reacciona al término holocausto que el entrevistador utiliza y reivindica la dimensión completamente histórica de la Shoah. Holocausto, del latín cristiano "holocaustum", 17 connota un sentido religioso antes que histórico.

La Shoah es un acontecimiento histórico aunque inconcebible, aunque es casi imposible comprender su alcance y su naturaleza. Sería demasiado fácil, dice Lanzmann, que se trate de una aberración de la historia: cuando lo decimos estamos escapando a su realidad, como se hace en la actualidad en Alemania. Las implicaciones de esta declaración son muy importantes. Veamos brevemente la etimología de la palabra aberración. Se trata de un "préstamo erudito (1624) del latín científico aberratio, derivado de aberrare, compuesto de ab (=a) y del verbo errar (=errer). Significa "acción de separarse" al hablar de una imagen óptica (1624); la palabra no se difunde sino en el siglo XVIII (Voltaire, por ejemplo) bajo la influencia del inglés, que lo emplea en ciencias. En sentido figurado (1775) significa también "desviación del buen sentido, de la razón" [...] Aberrantante (1811 en ciencias) es de uso corriente en el sentido de absurdo (::) "que se separa del tipo normal" o que "presenta variaciones anormales". ${ }^{18}$ La Shoah no es una des-

16 Claude Lanzmann with Roger Rosenblatt, produced and directed by D. Grubin, a presentation of Wnet/Thirteen, 1987, Educational Broadcasting Corporation.

17 "Sacrificio en que la víctima of recida a Dios se consume completamente por el fuego." Le Robert. Dictionnaire historique de la langue française, Dictionnaires Le Robert, París, 1993, p. 967.

${ }^{18}$ Le Robert, op. cit., p. 3. 
viación de la norma histórica, "no fue perpetrada por un grupo de bandidos", fue el producto de todo el aparato burocrático del Gran Estado moderno, fue el producto del consenso de la nación alemana y de la complicidad del mundo. No es una desviación, sino que es el resultado de miles de años de antisemitismo. El análisis de Lanzmann discute las nociones de progreso, de evolución, de democracia de una manera muy sutil, finalmente pone en cuestión la noción de historia como recorrido ascendente en donde las masacres serían las aberraciones.

Toda la entrevista es un juego muy interesante entre la lógica del entrevistador que quiere siempre reducir a la comprensión y a la clausura lo que no se deja ni comprender ni clausurar sin forzar las estructuras del pensamiento histórico y la investigación de Lanzmann que pone en cuestión todo el tiempo las categorías del pensamiento y que no se propone dilucidar la opacidad trágica de la Shoah.

A Rosenblatt que dice: "Entonces éste (holocausto) fue la consecuencia lógica de la vergüenza que ha aumentado durante miles de años", Lanzmann le responde: "es difícil utilizar el término "lógica". La verdadera cuestión es: cómo la primera medida antisemita que se tomó en 1933 condujo a Auschwitz y cómo no condujo a Auschwitz. Desde luego que condujo a Auschwitz, pero pudo no haber conducido ahí..." La historia se sitúa en la dinámica entre esas dos posibilidades. La película se llena de la escritura de esta dinámica.

En su poema audiovisual, La Rabbia, ${ }^{19}$ Pasolini nos da otro ejemplo de la posibilidad de comprender de nuevo el mundo mediante la poesía. Se trata de una película de montaje de materiales provenientes de los noticieros de la época -el principio de los años sesenta-. El tema de la película es la guerra. Mientras que las imágenes se siguen en la pantalla, dos voces

19 P. Pasolini, La Rabbia. Primera parte realizada por P. Pasolini; segunda parte realizada por G. Guareschi, 1963, Production: Opus Film 53'. 
en off, una en prosa y otra en poesía, las acompañan. No es un comentario, la relación entre el texto visual y el texto sonoro tiene más bien un carácter dialógico. La simpleza de las imágenes -incluso las imágenes más trágicas se hacen banales al ritmo de los noticieros organizadas en sectores de información- es superada y trastocada por las palabras en las que se inscriben las imágenes. El orden cronológico o lógico que, habitualmente, en un documental o en las noticias liga las imágenes está invertido. Se le remplaza por el orden "político-poético" de un discurso nuevo que no trata de representar la realidad, sino de inscribirse en su materialidad, de hacerla emerger en su complejidad, de producirla sobre la pantalla.

El ritmo de las imágenes junto con el de los versos y la naturaleza fuertemente visual de éstos producen una realidad histórica que desafía la organización del conocimiento, incluso bajo la forma de información, y la posición del sujeto en el mundo. Tomemos, por ejemplo, los versos sobre el color, "nuevo problema mundial". El color se materializa y se visualiza en los términos espaciales que se repiten con insistencia en el texto poético - "la nueva extensión del mundo se llama color"; "debemos aceptar las extensiones infinitas de vidas reales"; "ampliar la tierra" - y en la evocación de una diferencia viva que no se deja objetivar, hecha de miradas, de amores y de danzas. Una diferencia que no se convierte en un objeto de conocimiento, de representación, que provoca más bien nuevas formas de acción, contaminando nuestro modo de estar-en-el-mundo. Nuevas miradas, nuevas formas de amar, nuevas danzas se nos hacen familiares y las danzas, las miradas, los amores son también modos de conocimiento. Los versos no describen las imágenes, no las comentan, sino que las informan y éstas se inscriben en el sentido producido por esas palabras.

La práctica poética y cinematográfica de Pasolini lo llevan a una teoría de la Historia y de la temporalidad que se define 
fuera de las categorías occidentales del saber. El progreso, la dialéctica, todos los binarismos que caracterizan nuestra filosofía son puestos en cuestión por un materialismo que reconoce la persistencia del pasado en el presente, la coexistencia de lo racional y de lo irracional, la mentira del progreso...

Le monde sauvé par les gamins de Elsa Morante es también una reescritura poética de la Historia, la producción de una temporalidad no lineal y la realización de una filosofía de la acción sin un sujeto /protagonista que la lleve a cabo.

Para examinar este texto tan rico y tan denso podríamos plantearnos tres preguntas: ¿cuál temporalidad? ¿cuál subjetividad? ¿cuál "realidad"?

Cuando leemos el texto no estamos en presencia de un desarrollo lineal de un extremo a otro en el tiempo. No hay progreso. "Desde el instante en que la maquinaria escénica se pone en marcha, es imposible regular los movimientos. La sucesión de escenas es imprevisible", ${ }^{20}$ leemos en La chanson clandestine du Gran Opéra. En general, el texto pone en escena la temporalidad no lineal de la época de la mundialización, donde el tiempo se inscribe en una geografía y un imaginario transformados por la tecnología - el teléfono, la televisión, los periódicos, los aviones, la radio- que aproxima lugares lejanos y así como el encuentro de esos lugares lejanos, sumergidos en temporalidades diferentes, (como Trastevere y Nueva York) producto de las realidades nuevas. Realidades donde "los cometas de los Magos pasan por el camino de navíos lunares tan mezclados que se confunden con empolvamiento de las galaxias y de Hiroshimas". ${ }^{21}$ Todo el texto es muy interesante desde este punto de vista, pero por razones evidentes, es necesario que me limite a algunas observaciones sobre ciertas partes del texto. La soirée á Colone, por ejemplo, junto con

${ }^{20}$ E. Morante, Le monde sauvé par les gamins, Gallimard, París, 1991, p. 203.

21 E. Morante, op. cit., p. 84. 
los Antécédents sitúa la historia/acción en la temporalidad mítica de la tragedia, para restituirla inmediatamente en 1960 , por el servicio Neuro-delirios en la policlínica de una ciudad sud-europea, donde Antígona asiste a su padre, Edipo, internado. Los nombres de Edipo y Antígona nos conducen a la tragedia, pero la carta de recomendación de Edipo dice que él es un "pequeño propietario "acomodado", "viudo", de sesenta y tres años, alcohólico, que sufre de "alucinaciones visuales y auditivas". Combatió durante la Segunda Guerra Mundial en África donde se distinguió "por un exceso de crueldad y violencia contra prisioneros e indígenas..."22

La situación se complica más con el Coro: un conjunto de voces incoherentes que repiten frases "retomadas en parte de las documentaciones :de H.P., campos de concentración, discursos políticos y militares antiguos y modernos". Otras citas vienen "de antiguos cantos aztecas, de Sófocles, de un viejo blues de presidiarios, del Himno de los Muertos hebreo, de las Instrucciones a los reclutas de la Biblia", 23 de "historietas" y de la publicidad.

En esta temporalidad, el sujeto se fragmenta y se pluraliza.

No sé si Layo es culpable de Edipo, o Edipo de su padre, o si Yocasta tiene la culpa, ni si esta vejez que llora aquí es Layo, o Edipo, o su madre, o todos ellos, o todos los otros. [...] Sin embargo, el dolor es cierto. Es mi presencia. Me pertenece. Yo no soy alguien que asiste al dolor de un llamado Edipo. Soy yo este dolor $[\ldots]^{24}$

El yo ya no es más capaz de relatar, de garantizar la historia, de tomar distancia, de hacerse objeto de conocimiento, al mismo tiempo la Historia invade el sujeto, exige ser reinterpretada,

22 Ibidem, pp. 63-64.

23 Ibidem, p. 279.

24 Ibidem, pp. 85-86. 
rompe las ligas, una Historia que incluye muchas cosas que han sido negadas.

Los versos que componen La chanson du Gran Opéra constituyen otro ejemplo de reescritura de la Historia y una crítica muy lúcida de nuestra sociedad y de la Historia oficial. Farfada, perseguido por las Autoridades, no es un sujeto, es el "eficaz", la acción que nos ensañamos en transformar en objeto, que queremos identificar con un sujeto, pero sin lograrlo. Nos encontramos ante un sujeto multiforme, flotante, plural, que no garantiza la Historia, sino que más bien la hace explotar.

El historiador cree poder observar todos los lados del espectáculo cambiando continuamente de lugar. Pero mientras que observa los efectos de un lado, pierde de vista lo que pasa del otro lado y así sucesivamente. La secuencia: mirar desde un lugar antes y desde el otro después... no conduce a ninguna parte, debería verse todo al mismo tiempo, nos dicen los versos clandestinos de la Gran Ópera. La realidad es, quizás, todo ese conjunto y al mismo tiempo sin las particiones y las exclusiones que la historiografía occidental y las instituciones han querido instaurar. La irrealidad está hecha de esas particiones y exclusiones. Le monde sauvé par le gamins produce entonces una Historia que incluye la vida, más que volverse un himno a la vida contra la Historia.

Quizás la poesía, marginalizada con respecto de la prosa, escogida como vehículo de la verdad y garantía de la solidez del Estado, se convirtió en el terreno para la investigación y la experimentación fuera y contra los límites del saber institucionalizados; la poesía en la actualidad es sobre todo esa actividad revolucionaria. No tiene nada que ver con la disposición del texto en la página o con las rimas. Tiene más bien que ver con un ritmo que se opone a toda desmaterialización de la experiencia en la narración. La poesía reintroduce la materia en el lenguaje. Es entonces una práctica que promueve la revolución "no desde lo alto, ni desde lo bajo, sino de todas partes" 
para tomar prestadas las palábras del poeta español Antonio Machado.

\section{Metamorfosis}

Para concluir, me gustaría regresar al ensayo antes mencionado de Canetti y en particular, al concepto de metamorfosis que desempeña un papel importante en su filosofía y que anima también la obra y la práctica de otro gran intelectual del siglo $\mathrm{xx}$, Primo Levi.

La metamorfosis de la que habla Canetti no es sino la mediación, operada por la poesía, entre lo que ha sido separado. La eficacia de la poesía está en el desencadenamiento de las metamorfosis, de las transformaciones que hacen pasar a los seres y a los acontecimientos unos en otros.

Solamente por la metamorfosis, en el sentido extremo en que se emplea aquí esta palabra, llegaremos a sentir que un ser está detrás de sus palabras; no podremos captar de otra manera la consistencia real de lo que hay de vivo. Es un proceso misterioso, del que no hemos estudiado aún la naturaleza; y es sin embargo el único acceso verdadero al otro. Hemos buscado designar ese proceso de diferentes maneras; hablamos así de intuición o de empatía; por razones que no puedo exponer ahora, prefiero la palabra más exigente de "metamorfosis". Pero sea cual sea el nombre que le demos, nada osaría poner en duda seriamente que se trata ahí de algo real y muy precioso. En su puesta en práctica permanente, en la experiencia subyugante de seres de todo tipo, cualesquiera que sean, pero particularmente esos a los que se les considera menos; en esta práctica incesante, que no sería atrofiada ni paralizada por ningún sistema, vería yo el oficio propiamente dicho del poeta. ${ }^{25}$

${ }^{25}$ E. Canetti, op. cit., p. 340. 
En Canetti es el poeta, quien se impone, consciente de su responsabilidad, acoge por metamorfosis los seres y los saberes de los que "hace la experiencia". Pero poco importa la liga del escritor a un sujeto aún fundamentalmente humanista, el concepto de metamorfosis que Canetti nos propone evoca la dinámica que está en la base de una nueva Historia.

En el capítulo de Si c'est un homme de Primo Levi, titulado "El canto de Ulises", por ejemplo, Ulises, metamorfoseado en flama, pone en marcha la metamorfosis de Primo y de Pikolo que se convierten nuevamente en personas en una situación, a la que regresarán, que los metamorfoseó en "brutos" y así sucesivamente... podríamos continuar al infinito. El saber químico de Levi, que reconoce en la materia la base de todo saber, se metamorfosea en el saber histórico y existencial y el saber histórico y existencial en el saber literario y éste, de nuevo, en el saber histórico y existencial de otras personas, en otras situaciones: en Ruanda, en Bosnia, en Líbano, en Palestina, en Israel... al infinito. 